\title{
EFETIVIDADE DO CARÁTER EXTRAFISCAL DO IMPOSTO SOBRE CIRCULAÇÃO DE MERCADORIAS E SERVIÇOS
}

\section{ARTIGO ORIGINAL}

SANTOS, Victória Milaré Toledo ${ }^{1}$

SANTOS, Victória Milaré Toledo. Efetividade do caráter extrafiscal do imposto sobre circulação de mercadorias e serviços. Revista Científica Multidisciplinar Núcleo do Conhecimento. Ano 06, Ed. 08, Vol. 06, pp. 45-67. Agosto de 2021. ISSN: 2448-0959,

Link

de

acesso:

https://www.nucleodoconhecimento.com.br/lei/efetividade-do-carater,

DOI:

10.32749/nucleodoconhecimento.com.br/lei/efetividade-do-carater

\section{RESUMO}

O Imposto sobre a Circulação de Mercadorias e Serviços (ICMS) está previsto na Constituição Federal de 1988, que também disciplina sua natureza fiscal e extrafiscal. Em relação à citada natureza, formalizada pelo princípio constitucional da seletividade, pode-se supor a necessidade de observância da dignidade da pessoa humana e a busca pela justiça tributária como instrumentos de controle da tributação, a partir dos quais serão estabelecidos critérios valorativos acerca da conjuntura econômica e social. Nesse sentido, o presente artigo questiona se o caráter extrafiscal do ICMS, previsto na Carta Constitucional, tem cumprido seu objetivo originário, mostrando-se efetivo, e se essa característica pode ser entendida como instrumento de justiça tributária, de fato. Busca-se analisar essa questão norteadora sob uma perspectiva prática, a partir do julgamento em curso no Supremo Tribunal Federal (STF) do Recurso Extraordinário no 714.139 (Tema 745), em que se examina a efetiva aplicação do princípio da seletividade pelo Poder Público, averiguando se o direcionamento dispendido às questões debatidas nos autos se coaduna com os ditames constitucionais, consagrando o mencionado

\footnotetext{
${ }^{1}$ Mestranda em Direito Constitucional e Processual Tributário e Bacharel pela Pontifícia Universidade Católica de São Paulo (PUC/SP). ORCID: 0000-0002-2515-129X.
}

RC: 95841

Disponível em: https://www.nucleodoconhecimento.com.br/lei/efetividade-do-carater 
princípio como instrumento de justiça tributária. Adotando-se como pontos de partida uma breve abordagem histórica sobre a instituição do ICMS, sua natureza, e o referido julgamento, será evidenciado que os Estados-membros deveriam interpretar sistematicamente o Texto Constitucional, em atenção aos interesses da coletividade, mas que isso por vezes não ocorre - a despeito da previsão inicial do legislador constituinte originário. Por fim, concluir-se-á que não são raras as situações em que se nota incoerência no ordenamento jurídico quanto ao tema, demandando inúmeras provocações do Judiciário para análise de supostas violações, pela Administração Pública, dos direitos e garantias constitucionais dos contribuintes. Para tanto, como metodologia científica, serão utilizadas pesquisas legislativas, bibliográficas e jurisprudenciais, em especial o recurso mencionado, em curso no STF, buscando-se proporcionar informações quanto aos recentíssimos embates jurídicos acerca do tema.

Palavras-chave: Constituição Federal, ICMS, seletividade, justiça tributária.

\section{INTRODUÇÃO}

O Imposto sobre a Circulação de Mercadorias e Serviços (ICMS), previsto no artigo 155, inciso II, da Constituição Federal de 1988, é de competência dos Estadosmembros e do Distrito Federal e incide sobre as operações de circulação de mercadoria (inclusive sua importação), prestação de serviço de comunicação e de transporte interestadual e intermunicipal. Para além de definir as hipóteses de incidência do tributo, o Texto Constitucional prevê no parágrafo $2^{\circ}$, inciso III, desse mesmo dispositivo, o caráter seletivo em função da essencialidade da mercadoria e dos serviços (BRASIL, 2021c).

A partir do exame das características do tributo em questão, este estudo analisará o princípio da seletividade, que encontra previsão no artigo 145 , $1^{\circ}$, da Carta Constitucional, estabelecendo alíquotas diferenciadas conforme a essencialidade de mercadoria ou serviço. 
Nesse sentido, observa-se a necessidade de compreender sobre a utilização da própria Magna Carta como instrumento de efetivação da justiça tributária, tendo em vista o contexto de extrema desigualdade - na qual o conceito de "essencialidade" acaba por se alterar, justificando a provocação do Poder Judiciário pelos próprios contribuintes.

Para tanto, explora-se especificamente o julgamento em curso no Supremo Tribunal Federal do Recurso Extraordinário oㅜ 714.139, sob a relatoria do ministro Marco Aurélio Mello, em que se examina a efetiva aplicação do princípio da seletividade e a consequente observância do critério da essencialidade. Trata-se do tema ํㅜ 745 de repercussão geral, referente à aplicação da alíquota de $25 \%$ (vinte e cinco por cento) aos serviços de fornecimento de energia elétrica e serviços de comunicação, pelo Estado de Santa Catarina.

Portanto, o foco do presente estudo residirá na análise de um dos aspectos mais controversos no âmbito do Direito Constitucional Tributário até a presente data a respeito do tema: atualmente, o caráter extrafiscal do ICMS tem se mostrado efetivo, em observância à previsão da Constituição Federal? Essa extrafiscalidade pode ser entendida como instrumento de justiça tributária de fato, tal como pretendeu o legislador constituinte originário?

Visando alcançar todos os objetivos propostos, utiliza-se, no presente artigo, de metodologia que consiste fundamentalmente em consulta bibliográfica, realizada a partir da análise das legislações pertinentes ao tema, doutrinas especializadas, além do entendimento do STF que está se consolidando sobre o assunto objeto de estudo em sede de julgamento de recurso de repercussão geral.

\section{ICMS NA CONSTITUIÇÃO FEDERAL DE 1988}

Sob um contexto político caracterizado pela pressão de inúmeros grupos, dentre os quais se inseriam os Estados-membros buscando mudanças no tocante às questões tributárias (COÊLHO, 2007), foi editada a atual Carta Constitucional, que ampliou a competência tributária dos referidos entes. 
Segundo comentários da Professora Misabel Derzi à obra de Aliomar Baleeiro, o ICMS representa verdadeira adição ao Imposto sobre a Circulação de Mercadorias (ICM) anterior, originário do Imposto sobre Vendas e Consignações (IVC), "dos antigos impostos únicos federais sobre energia elétrica, combustíveis, lubrificantes e minerais do País" (BALEEIRO, 2013, p. 533). Seria também uma adição "dos impostos federais sobre transportes de pessoas e cargas que não fossem estritamente municipais e sobre comunicações" (BALEEIRO, 2013, p. 533).

Como antecipado, o ICMS está previsto na Constituição Federal de 1988 no artigo 155, inciso II e parágrafo $2^{\circ}$ (BRASIL, 2021c), sendo de competência dos Estadosmembros e do Distrito Federal[3]. Atualmente ele é regulamentado pela Lei Complementar $n^{\circ}$ 87/1996 (BRASIL, 2021d), conhecida como "Lei Kandir", que transfere a cada Estado-membro autonomia para estabelecer o quantum de cobrança do imposto. Assim, as Unidades Federadas podem tributar a operação relativa à circulação de mercadorias, à prestação de serviços de transporte interestadual e intermunicipal e os serviços de comunicação.

Para melhor compreensão, pode-se dizer que, a partir da atual Constituição, o antigo ICM incorporou os fatos geradores do Imposto sobre Serviços de Comunicação (ISSC), Imposto sobre Serviços de Transporte (ISST), os impostos únicos (tributos que envolviam energia elétrica, combustíveis, lubrificantes, minerais e energia elétrica) - todos de competência da União Federal - , bem como aqueles relativos ao Imposto sobre Serviços de Qualquer Natureza (ISSQN), apenas no tocante aos serviços de comunicação de natureza municipal (MOREIRA, 2020).

A Constituição Federal não se restringe a definir as hipóteses de incidência do imposto em foco. A partir de uma interpretação sistemática, o professor André Mendes Moreira (2020) ilustrou as hipóteses de incidência do tributo e suas consequências jurídicas.

Quanto ao primeiro item: a) o aspecto material é a "compra-e-venda de mercadoria (inclusive sua importação), prestação de serviço de comunicação e de transporte interestadual e intermunicipal" (MOREIRA, 2020, p. 328); b) o aspecto temporal é o 
"momento da saída da mercadoria, do desembaraço aduaneiro ou da prestação do serviço" (MOREIRA, 2020, p. 328); c) o aspecto espacial é definido por "qualquer lugar do território nacional e, nas hipóteses expressamente previstas na Constituição, no exterior" (MOREIRA, 2020, p. 328); e, por fim, d) o aspecto pessoal abarca o "comerciante, industrial, produtor, importador, prestador de serviço de comunicação e de transporte interestadual e intermunicipal" (MOREIRA, 2020, p. 328).

Em relação à consequência jurídica, o ilustre professor fez os seguintes apontamentos: a) os sujeitos ativos são os Estados-membros e o Distrito Federal, como visto; b) o sujeito passivo corresponde ao "comerciante, industrial, produtor, importador, prestador de serviço de comunicação e de transporte interestadual e intermunicipal" (MOREIRA, 2020, p. 328); c) a base de cálculo é o "valor da operação, da prestação ou da importação, este acrescido de II, IPI, IOF, despesas aduaneiras, taxas e contribuições alfandegárias" (MOREIRA, 2020, p. 328); d) a alíquota interna é livremente estabelecida pelos Estados e a interestadual é fixada pela Resolução do Senado Federal ㄲo 22/1989, sendo $7 \%$ ou $12 \%$, a depender do Estado de destino; e) o valor a pagar será "o valor dos débitos abatido dos créditos do imposto aos quais o contribuinte fizer jus" (MOREIRA, 2020, p. 328); e, por fim, f) o montante devido será pago da forma e no lugar previstos "no Regulamento do ICMS de cada Estado" (MOREIRA, 2020, p. 328).

Para mais, cumpre mencionar a classificação dos tributos entre diretos ou indiretos, de modo a indicar sua respectiva repercussão financeira, ou seja, a partir de tal denominação revela-se quem arcará pelo encargo decorrente da mercadoria, produto ou serviço.

Como explica Adolpho Bergamini (2019, p. 35), "no primeiro grupo se enquadram os tributos incidentes sobre a renda (IRPJ e CSLL, por exemplo) e sobre a propriedade (IPTU, IPVA, ITR etc.)"; os tributos indiretos correspondem àqueles que "oneram as operações/prestações (mercantis ou não) que viabilizam a prestação de serviços, circulação e/ou produção de mercadorias e/ou produtos, a exemplo do IPI, ICMS e ISS" (BERGAMINI, 2019, p. 35). Assim, em relação ao ICMS, sempre haverá a 
figura do contribuinte de direito e do contribuinte de fato, que será o adquirente final, aquele que efetivamente suportará a carga tributária da operação.

Para complementar as informações acerca do imposto em questão, insta destacar que a tributação sobre o consumo, uma forma de tributação indireta, já se perpetua no Brasil há certo tempo. Inclusive, o ICMS é o mais relevante imposto brasileiro sobre o consumo em termos de arrecadação[4].

Diante de sua imprescindibilidade em nosso ordenamento jurídico, não restam dúvidas de que o Estado deve seguir todos os preceitos estabelecidos na Constituição da República, dentre os quais inserem-se os princípios constitucionais, dos quais se passa a tratar.

\section{PRINCÍPIOS PREVISTOS PELA CONSTITUIÇÃO FEDERAL DE}

\section{8}

Sabe-se que os princípios são de suma importância ao ordenamento jurídico, à medida em que, além de versarem acerca de garantias e direitos dos indivíduos e da coletividade, suprem eventuais lacunas normativas, correspondendo a verdadeiras fontes do Direito[5].

Em relação à semântica do vocábulo "princípio", o professor Paulo de Barros Carvalho (1991) explica que expressa o "ponto de origem" e as formas de síntese com que se movimentam as meditações filosóficas. Em relação ao campo do Direito, ele explica que:

Este termo é utilizado para tratar das "regras de que falamos, mas também se emprega a palavra para apontar normas que fixam importantes critérios objetivos, além de ser usada, igualmente, para significar, o próprio valor, independentemente da estrutura a que está agregado e, do mesmo modo, o limite objetivo sem a consideração da norma. (CARVALHO, 2017, p. 167).

Sobre o tema, Gomes Canotilho (2003) explica que a Constituição é um sistema aberto de princípios, motivo pelo qual se deve ponderar e chegar a um ponto de concordância, conforme o peso de cada um desses e as circunstâncias do caso 
concreto. Destaca também que "embora a Constituição possa ser uma unidade dividida ( $P$. Badura) dada a diferente configuração e significado material das suas normas, isso em nada altera a igualdade hierárquica de todas as suas regras e princípios" (CANOTILHO, 2003, p. 1.184), em observância ao princípio da unidade da Constituição.

O célebre doutrinador apontado aduz ainda que as regras e princípios jurídicos constitucionais valem como lei, pois o direito constitucional é direito positivo (CANOTILHO, 2003). Neste sentido, fala-se na Constituição como norma e é ela própria que prescreve, expressamente, a aplicabilidade direta das normas de direitos, liberdades e garantias e, de forma indireta, a aplicabilidade das normas organizatórias.

Sendo assim, é possível entender que os princípios promovem valores, além de também caracterizarem-se, em certas situações, como limitações constitucionais ao poder de tributar. A despeito da Magna Carta não trazer em seu texto um rol de princípios, a partir do qual seria possível e numerá-los e identificá-los por completo, é possível extrair dois para análise do tema em questão, são eles: princípio da capacidade contributiva e princípio da seletividade. Vejamos.

\subsection{PRINCÍPIO DA CAPACIDADE CONTRIBUTIVA}

O princípio da capacidade contributiva está materializado no artigo $145, \S 1^{\circ}$, da Constituição Federal (BRASIL, 2021c)[6], e consiste em um poder-dever da Administração Tributária de avaliar os sinais indicadores de riqueza do contribuinte. Tem como destinatário, portanto, o próprio legislador ordinário das pessoas políticas (CARRAZZA, 2017).

A noção de capacidade contributiva, aliada à ideia de justiça fiscal, teve a sua origem no próprio surgimento do tributo, pois, desde o antigo Egito, entendia-se que os tributos deveriam relacionar-se com a riqueza daqueles que os pagariam (COSTA, 1993). É possível identificar na doutrina inúmeros conceitos acerca deste princípio, em razão do alto grau de generalidade da expressão. 
Para Regina Helena Costa (1993, p. 24), a capacidade contributiva, no plano jurídico-positivo, significa "que um sujeito é titular de direitos e obrigações com fundamento na legislação tributária vigente, que é quem vai definir aquela capacidade e seu âmbito". Já no plano ético-econômico, relaciona-se com a justiça econômica material. Corresponderia, portanto, à capacidade econômica do indivíduo para "suportar ou ser destinatário de impostos, que depende de dois elementos: o volume de recursos que o sujeito possui para satisfazer o gravame e a necessidade que tem de tais recursos" (COSTA, 1993, p. 25). Por fim, no plano técnicoeconômico, a capacidade contributiva apega-se à concepção segundo a qual teriam capacidade econômica os indivíduos que:

[...] a) constituam unidades econômicas de possessão e de emprego de recursos produtivos ou de riqueza; b) sejam facilmente identificáveis e avaliados pela Fazenda Pública como suscetíveis de imposição, e c) estejam em situação de solvência presumidamente suficiente para suportar o tributo. (COSTA, 1993, p. 25).

Pode-se entender o princípio da capacidade contributiva como a possibilidade econômica de pagar tributos (COÊLHO, 2007). Segundo Sacha Calmon Navarro Coêlho (op. Cit.), há duas classificações possíveis para tal instituto: subjetiva ou objetiva. A primeira considera apenas o indivíduo (capacidade econômica real); a segunda considera as manifestações objetivas da pessoa (ter certo objeto).

Para o professor, "o constituinte elegeu como princípio a capacidade econômica real do contribuinte" (COÊLHO, 2007, p. 84), motivo pelo qual a norma jurídica deverá trazer em seu texto todos os elementos suficientes para que, ao ser aplicada, sejam consideradas as especificidades econômicas de cada contribuinte, de forma individual.

Sendo assim, deverá o legislador analisar quais fatos indicam a capacidade contributiva do contribuinte, de modo a revelar suas respectivas manifestações de riqueza. Corresponde, neste sentido, a uma decisão verdadeiramente política a ser tomada. 
Neste contexto, insta mencionar que o princípio em questão se relaciona com o princípio da igualdade, além de ajudar a efetivar o princípio republicano no campo do Direito Tributário (CARRAZZA, 2017). Cuida-se, como visto, de disposição segundo a qual as pessoas devem pagar impostos na proporção de seus índices de riqueza, por isso as normas devem ser medidas pelo parâmetro da igualdade, de forma a buscar a justiça fiscal e voltando-se à minimização das disparidades sociais e econômicas.

Sobre o assunto, Roque Carrazza (2017) pontua que o princípio em foco se conecta também com o princípio da solidariedade, na medida em que aqueles que podem devem pagar impostos para o bem-estar de todos, inclusive daqueles que não o podem, pois isso privaria estes últimos do mínimo essencial de uma existência digna. Dessa forma, aqueles que podem ajudam a "remover os obstáculos de ordem econômica e social que limitam, de fato, a liberdade e a igualdade dos menos afortunados" (CARRAZZA, 2017, p. 105).

Em suma, o princípio da capacidade contributiva determina que os impostos devem exprimir um caráter pessoal, sendo graduados conforme a capacidade econômica dos contribuintes, de tal modo que a hipótese de incidência alcance aqueles indivíduos que possuam capacidade econômica suficiente para arcar com o encargo do respectivo tributo.

Ocorre que, à medida em que o imposto em foco é classificado como indireto, não é possível à lei determinar cada um dos consumidores finais. Assim, a seletividade foi estabelecida constitucionalmente como forma de garantir àqueles que suportam o encargo tributário o respeito ao princípio ora em enfoque. A brilhante professora Misabel Derzi demonstra essa questão em um de seus comentários à obra de Aliomar Baleeiro, aplicável perfeitamente à realidade do ICMS, ainda que trate do imposto sobre produtos industrializados (IPI) - também sujeito ao princípio da seletividade[7] - , in litteris:

Não podendo conhecer os consumidores, em escala de milhões, o legislador, olhos postos no princípio da capacidade contributiva, ao utilizar o princípio da seletividade, grava menos com o IPI os artigos essenciais. Justiça imperfeita, 
mas ainda justiça, pois José compra açúcar tanto quanto Simonsen, pelo mesmo preço pagando o mesmo IPI agregado ao preço. Em compensação, José não compra caviar mais tributado. Em suma, açúcar é essencial para todos em todo o território nacional. Para os pobres, principalmente para eles, em qualquer região do país, o preço do açúcar é essencial. (BALEEIRO, 2013, p. 492).

Destarte, ainda que o princípio em pauta não possa ser considerado para fins de gradação do tributo, ao menos pode ser considerado como indicador das hipóteses em que deverá conceder isenção total ou parcial da obrigação tributária, à luz do princípio da seletividade - a ser analisado no tópico seguinte. Cabe citar novamente a renomada professora Misabel, que expôs com precisão, também em um dos seus comentários à obra de Aliomar Baleeiro - Limitações Constitucionais ao Poder de Tributar -, sobre o tema:

O art. 145, $\S 1^{\circ}$, fala em pessoalidade sempre que possível. A cláusula sempre que possível não é permissiva, nem confere poder discricionário ao legislador. Ao contrário, o advérbio sempre acentua o grau de imperatividade e abrangência do dispositivo, deixando claro que, apenas sendo impossível, deixará o legislador de considerar a pessoalidade para graduar os impostos de acordo com a capacidade econômica subjetiva do contribuinte. E quando será impossível?

A doutrina costuma apontar a hipótese dos impostos que são suportados pelo consumidor final, como exemplo de tributação não-pessoal. É que, nos impostos incidentes sobre a importação, a produção ou a circulação, o sujeito passivo, que recolhe 0 tributo aos cofres públicos (o industrial ou comerciante), transfere a um terceiro, o consumidor final, os encargos tributários incidentes. Tornar-se-ia muito difícil, senão impossível, graduar o imposto sobre produtos industrializados ou sobre operação de circulação de mercadorias de acordo com a capacidade econômica da pessoa que adquire o produto ou a mercadoria para o consumo. Por isso, a Constituição Federal, seguindo a melhor doutrina, fala em pessoalidade sempre que possível e estabelece, em substituição, o princípio da seletividade para o Imposto sobre Produtos Industrializados e para o Imposto sobre Operações de Circulação de Mercadorias e Serviços nos arts. 153, §3ํㅡ, I, e 155, §2º, III.

O fenômeno, que estamos referindo, da translação ou da repercussão ocorrente nos impostos ditos 'indiretos', exigirá um tratamento especial frente aos dois princípios que estando pondo em contato e resolver-se-á, exclusivamente, na seletividade das alíquotas ou na isenção dos gêneros de primeira necessidade. É que a capacidade econômica demonstrada por quem tem aptidão para o consumo, somente está disponível para o pagamento de tributos, em se tratando de consumo de gêneros e produtos de necessidade média, de luxo ou supérfluos. Como nos alerta $F$. Moschetti em relação às mercadorias essenciais para a manutenção de uma existência digna, decente 
(alimentação, vestuário simples, certo número de medicamentos, etc), cabe isenção obrigatória pelo legislador. (BALEEIRO, 2006, p. 692-696).

É justamente neste contexto, diante dessa aplicação "imperfeita” (COÊLHO, 2007, p. 86) do princípio da capacidade contributiva ao ICMS, imposto classificado como indireto, que se passa a analisar a aplicação do princípio da seletividade.

\subsection{PRINCÍPIO DA SELETIVIDADE E A QUESTÃO DA ESSENCIALIDADE}

À luz do regime constitucional anterior, o ICM era um tributo caracterizado pelo seu caráter fiscal, visando principalmente ao abastecimento dos cofres públicos, pois contava, nos termos da Constituição Federal de 1967, com redação dada pela Emenda Constitucional № 23/1983, com alíquotas uniformes para todas as mercadorias nas operações internas e interestaduais, bem como nas interestaduais realizadas com consumidor final.[8]

Por sua vez, a atual Constituição Federal, em seu artigo 155, parágrafo 2ํㅡㄹ inciso III (BRASIL, 2021C), dispõe acerca da seletividade do atual Imposto sobre a Circulação de Mercadorias e Prestação de Serviços de Transporte Interestadual e Intermunicipal e de Comunicação (ICMS) em função da essencialidade das mercadorias e dos serviços. Vejamos:

Art. 155. Compete aos Estados e ao Distrito Federal instituir impostos sobre: (Redação dada pela Emenda Constitucional ํㅜ 3, de 1993) [...]

II - operações relativas à circulação de mercadorias e sobre prestações de serviços de transporte interestadual e intermunicipal e de comunicação, ainda que as operações e as prestações se iniciem no exterior; (Redação dada pela Emenda Constitucional no 3, de 1993) [...]

$\S 2^{\circ}$. O imposto previsto no inciso II atenderá ao seguinte: (Redação dada pela Emenda Constitucional no 3, de 1993) [...]

III - poderá ser seletivo, em função da essencialidade das mercadorias e dos serviços; [...]. (BRASIL, 2021c).

Insta mencionar que "essência" significa o que faz parte da natureza das coisas; essencial, por sua vez, seria aquela parte indispensável a algo. A despeito de a 
Constituição Federal não trazer um rol de mercadorias e serviços considerados essenciais para fins da aplicação do princípio da seletividade, a noção de "essencialidade" foi exposta com maestria por Aliomar Baleeiro (2013, p. 491), para quem o termo se referia à "adequação do produto à vida do maior número dos habitantes do país". Ele complementa da seguinte forma:

As mercadorias essenciais à existência civilizada deles devem ser tratadas mais suavemente, ao passo que as maiores alíquotas devem ser reservadas aos produtos de consumo restrito, isto é, o supérfluo das classes de maior poder aquisitivo. Geralmente, são os artigos mais raros e, por isso, mais caros. Do ponto de vista econômico, a norma inspira-se na utilidade marginal. Do ponto de vista político, reflete as tendências democráticas, e até mesmo socialistas, do mundo contemporâneo, no qual os países civilizados seguem orientação idêntica. (BALEEIRO, 2013, p. 491).

Nesse contexto, percebe-se que as mercadorias e serviços "essenciais" para o legislador constitucional seriam aqueles que atendessem às necessidades básicas dos cidadãos, podendo ser caracterizados de tal forma de modo a assegurar a dignidade da pessoa humana e o mínimo existencial. Caso contrário, a variação das alíquotas do ICMS poderia contribuir para o aumento das desigualdades sociais um dos objetivos perseguidos pela Carta Constitucional de 1988.

Vê-se, assim, que, com o regime constitucional inaugurado em 1988, a natureza do tributo passa a ser fiscal e extrafiscal[9], concomitantemente[10], porque, conforme explica Adolpho Bergamini (2019, p. 52), "sua vocação não é apenas constituir importante fonte de receita aos entes competentes à sua instituição, mas também propiciar a facilitação da circulação de mercadorias e prestação de serviços essenciais à sociedade".

A partir do dispositivo constitucional transcrito, é possível definir o princípio da seletividade como uma forma de gradação da incidência tributária sobre produtos, mercadorias ou serviços, conforme sua essencialidade. Ou seja: quanto mais importante e imprescindível determinado bem puder ser considerado à sociedade, menor será a carga tributária incidente sobre ele. 
O princípio constitucional em questão (considerando, especificamente, a perspectiva dos seus conteúdos materiais de seleção, tal como a essencialidade) pode ser entendido como um subprincípio da capacidade contributiva, conforme já destacava o professor Ricardo Lobo Torres (2009). Para ele, a essencialidade poderá ser graduada de tal forma que "a alíquota ou não existirá, quando o produto se tornar absolutamente essencial para atender às necessidades primárias, ou será fixada em escala ascendente na proporção em que menor for a sua utilidade social" (TORRES, 2014, p. 333).

Neste sentido, a fim de favorecer aqueles que suportam a carga econômica, as operações com mercadorias de primeira necessidade (essenciais) e as prestações de serviço de massa, sejam de transporte ou comunicação, deveriam ser completamente isentas do ICMS, "já que em relação a elas o contribuinte não tem liberdade de escolha" (CARRAZZA, 2020, p. 467). Para tanto, observa-se apenas a finalidade da mercadoria ou serviço, desconsiderando quaisquer outras variáveis.

A seletividade prevista pela Carta Constitucional é, então, uma forma de concretizar o princípio da capacidade contributiva nos impostos indiretos, visando à aplicação de uma maior carga tributária de produtos ou serviços supérfluos ou não essenciais, os quais, normalmente, são acessíveis a pessoas com maior poder aquisitivo. Para Leandro Paulsen (2018, p. 159), a técnica da seletividade implica "múltiplos tratamentos tributários, adequados a cada objeto". Ele explica também que:

Certo é, em regra, que os produtos essenciais são consumidos por toda a população e que os produtos supérfluos são consumidos apenas por aqueles que, já tendo satisfeito suas necessidades essenciais, dispõem de recursos adicionais para tanto. A essencialidade do produto, portanto, realmente constitui critério para diferenciação das alíquotas que acaba implicando homenagem ao princípio da capacidade contributiva. (PAULSEN, 2018, p. 161).

Supõe-se, portanto, que, para aplicação do princípio da seletividade, deve-se observar a dignidade da pessoa humana e buscar a justiça tributária como instrumentos de controle da tributação, a partir dos quais serão estabelecidos critérios valorativos acerca da conjuntura econômica e social. Além da coletividade, deve ser observada a perspectiva individual, visando entender as reais 
necessidades da população como um todo e intentando que o princípio em foco seja aplicado de modo coerente, com a consequente preservação do direito de todos os envolvidos.

O princípio constitucional poderá ser efetivado por intermédio do manejo das alíquotas do imposto, pela redução de sua base de cálculo, pela criação de incentivos fiscais etc. A seletividade poderá ser alcançada pelo emprego de qualquer técnica que vier a alterar, de forma significativa, a carga tributária (CARRAZZA, 2020), resultando na redução do encargo repassado ao contribuinte de fato. Dessa forma, conforme a natureza ou a finalidade dos bens, produtos ou mercadorias, estes serão privilegiados ou isentos com base na essencialidade que possuírem frente às necessidades da população.

Sendo assim, é possível concluir que a seletividade, prevista pela Constituição Federal de 1988, serve também como uma forma direta de controle e incentivo comercial aos bens ou serviços de maior necessidade; afinal, qualquer alteração no encargo econômico-tributário repassado no preço de venda repercute ao consumidor final.

Em relação ao anteriormente transcrito inciso III, do parágrafo $2^{\circ}$, do artigo 155 , da Carta Constitucional (BRASIL, 2021c), percebe-se que não há expressa determinação para aplicação do princípio da seletividade. Pelo contrário, o termo "poderá" causar divergência na doutrina e jurisprudência quanto ao caráter cogente da aplicação do princípio em questão especificamente em relação ao ICMS.

Para José Eduardo Soares de Melo (2020), trata-se de princípio constitucional a ser rigorosamente obedecido no âmbito do IPI, e de modo permitido no caso do ICMS. De modo contrário, o ilustre doutrinador Roque Carrazza aduz que:

[...] Vamos logo consignando que este singelo "poderá" equivale juridicamente a um peremptório "deverá". Não se está, aqui, diante de mera faculdade do legislador, mas de norma cogente - de observância, pois, obrigatória.

Além disso, quando a Constituição confere a uma pessoa política um "poder", ela, ipso facto, está Ihe impondo um "dever". É por isso que se costuma falar 
que as pessoas políticas têm poderes-deveres (ou, como mais apropriadamente proclama Celso Antônio Bandeira de Mello, deveres poderes). [...]

Portanto, a seletividade no ICMS, tanto quanto no IPI, é obrigatória. Melhor elucidando: o ICMS deverá ser seletivo em função da essencialidade das mercadorias e dos serviços. (CARRAZZA, 2020, p. 466).

A partir de uma interpretação sistemática da Carta Constitucional é possível alcançar a ideia de que o verbo "poderá", na realidade, corresponde a verdadeiro dever do aplicador da lei. Ao contrário do quanto disposto expressamente na Constituição Federal de 1967, em que as alíquotas do ICM eram uniformes, como restou demonstrado, não se pode cogitar neste momento, uma seletividade facultativa. Deve ser observado o princípio da capacidade contributiva, aplicando-se em foco aos bens e serviços conforme sua essencialidade: quanto maior sua relevância, menor deverá ser a alíquota incidente.

Neste sentido, averígua-se justamente o caráter extrafiscal do ICMS como instrumento de justiça tributária, a partir da observância aos ditames constitucionais estudados. Tendo em conta a obrigatoriedade da seletividade, tal como exposta, questiona no tópico precedente se é, de fato, possível afirmar que o princípio da seletividade está cumprindo seu objetivo previamente traçado.

\section{SELETIVIDADE DO ICMS COMO INSTRUMENTO DE JUSTIÇA TRIBUTÁRIA}

Conforme explicado nos tópicos anteriores, o ICMS é classificado como imposto indireto, à medida em que o ônus tributário recai sobre o consumidor final, o contribuinte de fato. Como regra, o citado imposto deveria incidir de forma proporcional, tendo em vista que não leva em conta a capacidade contributiva do consumidor; entretanto, por esta razão, o Texto Constitucional se preocupou em instituir o princípio da seletividade, determinando a aplicação de alíquotas diferenciadas conforme a essencialidade das mercadorias e serviços. 
Assim, viabilizou-se a observância à capacidade contributiva nos impostos indiretos, tais quais o próprio ICMS. Com isso, buscou o constituinte originário garantir a justiça tributária àqueles que mais dela necessitam. Sobre o tema, o renomado professor Paulo de Barros leciona que:

Princípio da justiça é uma diretriz suprema. Na sua implicitude, penetra de tal modo as unidades normativas do ordenamento que todos o proclamam, fazendo dele até um lugar comum, que se presta para justificar interesses antagônicos e até desconcertantes. Como valor que é, participa daquela subjetividade que mencionamos, ajustando-se diferentemente nas escalas hierárquicas das mais variadas ideologias. Os sistemas jurídicos dos povos civilizados projetam-no para figurar no subsolo de todos os preceitos, seja qual for a porção da conduta a ser disciplinada.

Realiza-se o primado da justiça quando implementamos outros princípios, o que equivale a elegê-lo como sobreprincípio. E na plataforma privilegiada dos sobreprincípios ocupa o lugar preemiente. Nenhum outro o sobrepuja, ainda porque para ele trabalham. Querem alguns, por isso mesmo, que esse valor se apresente como o sobre princípio fundamental, construído pela conjunção eficaz dos demais sobreprincípios. (CARVALHO, 2017, p. 172).

Os produtos da cesta básica, por exemplo, estão dentre as mais essenciais mercadorias em circulação no País, pois todos os cidadãos consomem tais produtos - desde aqueles mais carentes até aqueles que possuem maior poder aquisitivo. Nessa linha, os Estados-membros deliberaram, por meio de convênios, que a carga de ICMS sobre a cesta básica poderia ser reduzida ao patamar de 7\%, muito inferior às alíquotas comuns de $17 \%$ ou 18\% (PAULSEN, 2018), buscando atender à disposição constitucional.

No contexto de efetivação da justiça tributária, seria possível afirmar, contudo, que a previsão constitucional da seletividade gozaria de discutível objetividade, afinal, ela está intimamente ligada à noção de essencialidade, que poderia ser entendida, em um primeiro momento, como um conceito indeterminado e absolutamente variável, considerando que a própria Constituição da República de 1988 não o definiu.

Destarte, após uma melhor análise, chegar-se-á à conclusão de que o legislador não é livre para eleger, segundo critérios de conveniência e oportunidade, o que é ou o que não é essencial ou supérfluo. Deve buscar agir em conformidade com o Direito 
posto, diligenciando para exercer corretamente a competência que the foi outorgada pela Magna Carta.

Sobre o tema, Fábio Canazaro (2015, p. 154) ratifica tal ponto de vista, ao definir que as mercadorias e serviços essenciais, sob o ponto de vista jurídico, seriam aquelas "cujos valores constitucionais denotam ser indispensáveis à promoção da liberdade, da segurança, do bem-estar, do desenvolvimento, da igualdade e da justiça - ou seja, das finalidades constitucionalmente prescritas". Ora, diante das inúmeras situações passíveis de serem abarcadas pelas normas estaduais, sequer se pode cogitar que o eventual estabelecimento de termos obrigatórios ou hipóteses taxativas vinculadas à questão da essencialidade seria medida útil à efetividade da justiça tributária.

Nesse contexto, cabe relembrar que a sociedade está em constante evolução, de modo que eventual conceito jurídico estabelecido na Carta Constitucional poderia não acompanhar essas rápidas mudanças. A atual noção de essencialidade poderá variar rapidamente, não justificando qualquer taxatividade da norma constitucional que pudesse ser sugerida. Assim, justamente ao não determinar tal conceito jurídico, a Constituição permite que o aplicador da norma possa empenhar-se na busca pelo bem comum.

Dessa forma, os Estados-membros interpretam sistematicamente o Texto Constitucional, em atenção aos interesses da coletividade, para adotarem alíquotas seletivas para o ICMS. O renomado professor Sacha Calmon faz, contudo, a seguinte ressalva: "Adotada que seja a seletividade, tem o contribuinte o direito de provocar o Judiciário para que declare, à luz de critérios técnicos e dos aspectos sociais da Nação, se esta ou aquela mercadoria é supérflua" (COÊLHO, 2015, p. 326).

Não obstante, cumpre destacar que não são raras as situações em que se nota incoerência no ordenamento jurídico quanto ao tema, demandando inúmeras provocações do Judiciário para análise de supostas violações, pela Administração Pública, dos direitos e garantias constitucionais dos contribuintes. 
Nesse particular, analisa-se a efetiva aplicação do princípio da seletividade, especificamente no tocante à tributação dos serviços de fornecimento de energia elétrica e serviços de comunicação.

\subsection{ANÁLISE DO RECURSO EXTRAORDINÁRIO № 714.139}

Como antecipado, o Direito Constitucional buscou pautar a distribuição da carga tributária visando efetivar a justiça tributária, de modo que o ônus recaia de forma isonômica nos diferentes grupos sociais. Assim, o Estamos-membros se encontram submetidos a tais parâmetros do sistema jurídico no tocante, especificamente, às questões tributárias.

Dentro desse campo de liberdade interpretativo do Direito, exposto nos tópicos antecedentes, faz-se necessário verificar se determinada alíquota estabelecida é justa e observa aos ditames constitucionais. Para tanto, pondera se a mercadoria ou serviço em questão ocupa uma posição de primeira necessidade no consumo da população em geral.

Como exemplo, cita-se os serviços de fornecimento de energia elétrica e de comunicação - inquestionavelmente indispensáveis à toda a população —, aos quais foi estabelecida uma alíquota de $25 \%$ (vinte e cinco por cento) pelo Estado de Santa Catarina[11], equiparando-os a operações com produtos supérfluos.

Essa nítida inconsistência presente no ordenamento jurídico estadual foi motivo para impetração de mandado de segurança. A contribuinte Impetrante defendeu tratar-se de tratamento diferenciado e discriminatório pelo Estado em relação à alíquota fixada para outros produtos, submetidos ao regime ordinário, fixada no patamar de $17 \%$ (dezessete por cento). Assim, patente a violação aos princípios constitucionais da isonomia e da seletividade e essencialidade - artigos 150, II, e 155, § $2^{\circ}$, III, da Constituição Federal (BRASIL, 2021c).

O juízo de primeira instância e o Tribunal de Justiça do Estado de Santa Catarina (TJSC) decidiram pela constitucionalidade do artigo 19, inciso I, alínea 'a', da Lei 
Estadual ํo 10.297/1996, principalmente porque o princípio constitucional da seletividade, tratado anteriormente, envolveria uma faculdade e não uma imperatividade, em razão do termo "poderá", previsto no Texto Constitucional. Isto é, embora seja inequívoca a importância e a essencialidade da energia elétrica e dos serviços de comunicação, ambas as instâncias do TJSC entenderam não restar demonstrada a violação à seletividade.

$\mathrm{Na}$ sequência, a controvérsia teve a sua repercussão geral reconhecida pelo Supremo Tribunal Federal nos autos do Recurso Extraordinário № 714.139, sob a relatoria do ministro Marco Aurélio Mello (BRASIL, em julgamento) - Tema oㅜ 745 . Com o regular processamento do feito, a Procuradoria-Geral da República (PGR) manifestou-se pelo parcial provimento do recurso, em parecer com a seguinte ementa:

RECURSO EXTRAORDINÁRIO. REPERCUSSÃO GERAL. TEMA 745. ICMS. ARTS. 150, II, E 155, $\S 2 \%$, III, DA CONSTITUIÇÃO FEDERAL. SELETIVIDADE E ESSENCIALIDADE. ENERGIA ELÉTRICA E TELECOMUNICACÕES. ALÍQUOTA ESPECÍFICA SUPERIOR À ALÍQUOTA GERAL. INCONSTITUCIONALIDADE. PROVIMENTO. MODULAÇÃO DE EFEITOS RECOMENDÁVEL.

1. É inconstitucional o art. 19, inciso II, alíneas "a" e "c", da Lei estadual 10.297/1996 de Santa Catarina no que prevê alíquotas do ICMS superiores à geral a incidirem sobre energia elétrica e serviços de telecomunicações, por incompatibilidade com 0 princípio da seletividade/essencialidade.

2. Eliminada a regra especial que estipula alíquota majorada para energia elétrica e telecomunicações, tem-se que o ICMS de ambas cairá automaticamente na regra geral do Estado-membro e o contribuinte terá direito de pleitear a restituição dos valores pagos nos últimos cinco anos, nos termos do art. 168 do Código Tributário Nacional, não havendo falar em ofensa à separação de poderes por ativismo Judicial.

3. Concretiza o princípio da igualdade tributária a instituição, a partir de níveis reduzidos de consumo, de alíquotas 
progressivas na energia fornecida à população economicamente mais vulnerável, ao contrário do que sugere o recorrente, não havendo falar em ofensa ao art. 150, II, da Constituição. 3. Parecer pelo provimento parcial do recurso extraordinário.

4. Por colocar em risco a segurança jurídica e veicular matéria de excepcional interesse social, recomenda-se a modulação dos efeitos pro futuro, com estipulação de prazo razoável para adaptação da legislação do ICMS pelo Legislativo catarinense. (Procuradoria-Geral da República, 2015, n. 1106/2015).

Em sessão virtual realizada entre os dias 05/02/2021 e 12/02/2021, o Relator Ministro Marco Aurélio iniciou o julgamento do referido recurso destacando que o legislador estadual previu alíquotas diferenciadas do ICMS, utilizando-se, para tanto, da seletividade. Desse modo, o critério a ser observado pelo Estado de Santa Catarina não poderia ser outro senão o da essencialidade, afinal, seria contrário à própria Carta Constitucional exigir uma alta carga tributária à bens e serviços de primeira necessidade, como in casu.

Neste sentido, para o eminente Relator, houve verdadeiro desvirtuamento da técnica da seletividade, não se compatibilizando com os fundamentos e objetivos contidos no Texto Constitucional, a teor dos artigos $1^{\circ}$ e $3^{\circ}$, sob o ângulo da dignidade da pessoa humana ou da perspectiva do desenvolvimento nacional. Para ele:

Em sendo o ICMS tributo indireto, qual seria o referencial para aferir-se a capacidade contributiva? Já o esclareceu este Tribunal, em precedente da lavra do ministro IImar Galvão, no recurso extraordinário no 213.396. Nada obstante o recolhimento seja efetuado por contribuinte de direito designado por lei, a capacidade para contribuir é revelada a partir do consumidor dos bens e serviços, na condição de contribuinte de fato, uma vez ser a ele atribuído o ônus fiscal. Não há óbice à conjugação dos princípios da seletividade, progressividade e capacidade contributiva, visando maximar a justiça fiscal. (BRASIL, em julgamento).

À vista disso, o Ministro Relator Marco Aurélio votou pelo parcial provimento ao recurso para reformar o acórdão recorrido, deferindo a ordem e reconhecendo o direito da contribuinte ao recolhimento do ICMS incidente sobre a energia elétrica e 
serviços de telecomunicação, considerada a alíquota geral de 17\% (dezessete por cento).[12]

Sob outra perspectiva, o Ministro Alexandre de Moraes abriu divergência na votação ao dar parcial provimento ao recurso apenas para afastar a alíquota de $25 \%$ (vinte e cinco por cento) incidente sobre os serviços de comunicação, mantendo-se a alíquota neste patamar aos serviços de energia.

Em sua fundamentação referente aos serviços de energia elétrica, o referido Ministro pontuou que a legislação estadual aplicou o princípio da seletividade do ICMS em conjunto com o princípio da capacidade contributiva, visando à extrafiscalidade do tributo, o que estaria em consonância com a Constituição Federal, não havendo que se falar em violação ao princípio da isonomia tributária. Por outro lado, em relação aos serviços de comunicação, o Estado de Santa Catarina adotou a alíquota majorada sem qualquer justificativa para tanto, desconsiderando sua essencialidade.[13]

O julgamento foi suspenso por pedido de vista do Ministro Dias Toffoli, em 11/02/2021. Na sequência, foi reiniciado em 11/06/2021, tendo sido, novamente, suspenso por pedido de vista do Ministro Gilmar Mendes em 12/06/2021.

Pois bem. A partir de tais exposições, não restam dúvidas de que pode o Poder Judiciário verificar se o princípio da seletividade foi respeitado à luz do caso concreto pelo ente público. Entretanto, o Estado-membro deverá buscar agir sempre dentro dos limites que a lei lhe proporciona.

Tal como no caso ora apresentado, deve o contribuinte analisar se as alíquotas aplicadas observam o princípio da capacidade contributiva e consequentemente 0 princípio da seletividade. Sacha Calmon (2015, p. 326) bem pontua sobre o tema que "adotada que seja a seletividade, tem o contribuinte o direito de provocar o Judiciário para que declare, à luz de critérios técnicos e dos aspectos sociais da Nação, se esta ou aquela mercadoria é supérflua". 
Nesse sentido, além de verificar a observância, pelo Poder Público, aos princípios constitucionais, deverá o contribuinte analisar se as mercadorias e serviços essenciais ou não supérfluos estão sendo menos tributados do que aqueles que não o são. Pois, caso contrário, haverá ofensa direta à própria Constituição Federal, como demonstrado, de tal forma que a justiça tributária estará cada vez mais distante de ser atingida.

\section{CONSIDERAÇÕES FINAIS}

A partir do estudo em questão, permitiu-se conhecer uma outra perspectiva quanto ao tema da extrafiscalidade do ICMS. Como visto, o ICMS conta tanto com o caráter fiscal, de modo a atender ao objetivo principal da Administração Pública arrecadação -, como também com o caráter extrafiscal. Extrafiscalidade, como bem pontuava Geraldo Ataliba, pode ser definida como a utilização deliberada do tributo para finalidades não financeiras, mas regulatórias de comportamentos sociais, em matéria econômica, social e política (ATALIBA, 1966, p. 151).

No presente trabalho, partiu-se de uma análise das próprias características do tributo em questão. A intenção foi questionar se, atualmente, o referido caráter extrafiscal cumpre seu objetivo originário. Ou seja, buscou-se questionar se é possível entender, atualmente, a extrafiscalidade, no âmbito do Imposto sobre Circulação de Mercadorias e Serviços, como instrumento de justiça tributária, tal qual a intenção do legislador constituinte originário, mas que hoje se questiona.

Inicialmente, constatou-se que o princípio da capacidade contributiva foi editado exatamente com o objetivo de o legislador ordinário aferir quais fatos revelam as manifestações de riqueza dos contribuintes e, por intermédio de uma decisão verdadeiramente política, dispor sobre o tema. Assim, visando atingir uma justiça tributária, também sob uma disposição do constituinte originário, passa-se a determinar quais indivíduos deverão pagar impostos em cada situação em concreto.

Foi possível também observar que, a partir de uma interpretação sistemática do Texto Constitucional, a seletividade, prevista artigo 155 , parágrafo $2^{\circ}$, inciso III, é 
obrigatória, a despeito do termo utilizado no texto legal e ao contrário da previsão constante no ordenamento constitucional anterior, no qual as alíquotas do ICM eram uniformes.

Assim, entendeu-se a partir do presente trabalho que a Constituição da República se preocupou em instituir o princípio da seletividade, determinando a aplicação de alíquotas diferenciadas conforme a essencialidade das mercadorias e serviços na situação concreta, viabilizando, por consequência, a observância à capacidade contributiva nos impostos indiretos, especificamente no ICMS.

Contudo, a possível generalidade do termo "essencialidade", presente no dispositivo mencionado anteriormente, não se consubstancia em permissão ao aplicador da norma para uma definição arbitrária deste quesito. À luz das normas jurídicas brasileiras e da realidade social, é possível definir se determinada mercadoria ou serviço poderá ser compreendida e definida como algo de primeira necessidade no consumo da população em geral e, portanto, ser compatível, ou não, com o caráter da essencialidade

Ocorre que, a despeito da intenção do legislador constituinte originário ao elaborar a Constituição Cidadã, constatou-se ao longo deste estudo situações de incoerência no ordenamento jurídico no que se refere à efetividade da aplicação do princípio da seletividade. Afinal, como visto, tal princípio está intrinsecamente ligado ao conceito de essencialidade, que a própria Constituição não definiu, resultando em termo indeterminado e absolutamente variável.

Para melhor análise prática do tema, examinou-se o Recurso Extraordinário nº 714.139-SC, ainda em curso, em que se discute a aplicação de alíquota de $25 \%$ (vinte e cinco por cento) a serviços considerados absolutamente essenciais, quais sejam: fornecimento de energia elétrica e comunicação.

Sendo assim, após a leitura do presente artigo será possível concluir que o regramento da seletividade, aliado à noção da essencialidade, não tem sido efetivamente observado pelo Poder Público, motivo pelo qual os contribuintes têm 
recorrido ao Poder Judiciário a fim de garantir a imperatividade do texto constitucional. À medida em que alíquotas elevadas são estabelecidas desconsiderando a essencialidade das mercadorias e serviços e sem qualquer justificativa para tanto, há clara violação pelo Poder Público dos princípios constitucionais da isonomia e da seletividade.

Nesse sentido, a resposta à pergunta problema que norteou este estudo é negativa, pois não é possível suscitar a efetividade do caráter extrafiscal do ICMS como instrumento de justiça tributária, tendo em vista que os contribuintes precisam se socorrer a embates administrativos e jurídicos para pleitear o que já, "supostamente", estaria previsto pela Constituição Federal.

Em suma, todos os apontamentos expostos demonstram que a questão em debate é de extrema importância à medida em que, como visto, segue sendo objeto de recentes discussões pelos Tribunais Superiores e pela doutrina nacional especializada.

\section{REFERÊNCIAS}

ATALIBA, Geraldo. Sistema Constitucional Tributário Brasileiro. São Paulo: Revista dos Tribunais, 1966.

BALEEIRO, Aliomar. Limitações Constitucionais ao Poder de Tributar, $7^{\underline{a}}$ ed. Rio de Janeiro: Forense, 2006.

Direito Tributário Brasileiro, 12 $2^{\mathrm{a}}$ ed. Atualizada por Misabel Abreu Machado Derzi. Rio de Janeiro: Forense, 2013.

BERGAMINI, Adolpho. ICMS: análise de legislação, manifestações de administrações tributárias, jurisprudência administrativa e judicial e abordagem de temas de gestão tributária, 4aㅡ ed. rev., atual. e ampl. São Paulo: Thomson Reuters Brasil, 2019. 
BRASIL. Câmara dos Deputados. Decreto-Lei № 4.657, de 4 de setembro de 1942. Lei de introdução ao Código Civil Brasileiro. Brasília: Câmara dos Deputados, [2021a]. Disponível em: https://www2.camara.leg.br/legin/fed/declei/19401949/decreto-lei-4657-4-setembro-1942-414605-publicacaooriginal-68798-pe.html. Acesso em: 20 jun. 2021.

. Presidência da República. Emenda Constitucional № 23, de 1ํ de dezembro de 1983. Altera dispositivos da Constituição Federal. Brasília: Presidência da República, [2021b]. Disponível em: http://www.planalto.gov.br/ccivil_03/constituicao/emendas/emc_anterior1988/emc2383.htm. Acesso em: 20 jun. 2021.

. [Constituição (1988)]. Constituição da República Federativa do Brasil de 1988. Brasília, DF: Presidência da República, [2021c]. Disponível em: http://www.planalto.gov.br/ccivil_03/constituicao/constituicao.htm. Acesso em: 20 jun. 2021.

Presidência da República. Lei Complementar № 87, de 13 de setembro de 1996. Dispõe sobre o imposto dos Estados e do Distrito Federal sobre operações relativas à circulação de mercadorias e sobre prestações de serviços de transporte interestadual e intermunicipal e de comunicação, e dá outras providências. (LEI KANDIR). Brasília: Presidência da República, [2021d]. Disponível em: http://www.planalto.gov.br/ccivil_03/leis/lcp/lcp87.htm. Acesso em: 20 jun. 2021.

. Secretaria do Tesouro Nacional. Estimativa da Carga Tributária Bruta no Brasil - 2019. Brasília, DF: Secretaria do Tesouro Nacional, março de 2020. Disponível em: https://sisweb.tesouro.gov.br/apex/f?p=2501:9::::9:P9_ID_PUBLICACAO:32076. Acesso em: 23 jun. 2021. . Ministério da Economia; Secretaria do Tesouro Nacional. Estimativa da Carga Tributária Bruta do Governo Geral - 2020. Brasília, DF: Ministério da Economia; Secretaria do Tesouro Nacional, março de 2021 [2021e]. Disponível em: 
https://sisweb.tesouro.gov.br/apex/f?p=2501:9::::9:P9_ID_PUBLICACAO:38233. Acesso em: 23 jun. 2021.

. Supremo Tribunal Federal. Recurso Extraordinário no 714.139/SC. Recorrente: Lojas Americanas S/A. Recorrido: Estado de Santa Catarina. Relator: Min. Marco Aurélio Mello, julgamento em curso. Movimentação disponível em: http://portal.stf.jus.br/processos/detalhe.asp?incidente=4307031. Acesso em: 20 jun. 2021.

CANAZARO, Fábio. Essencialidade Tributária: igualdade, capacidade contributiva e extrafiscalidade na tributação sobre o consumo. Porto Alegre: Livraria do Advogado, 2015.

CANOTILHO, J. J. Gomes. Direito Constitucional e Teoria da Constituição, $7^{\text {a }}$ ed. Coimbra: Almedina, 2003.

CARRAZZA, Roque Antônio. Curso de Direito Constitucional Tributário, $31^{\text {a }}$ ed. rev. ampl. e atual. até a Emenda Constitucional n. 95/2016. São Paulo: Malheiros, 2017.

. ICMS, 18 ${ }^{\text {a }}$ ed. rev. e ampl. até a EC nำ 104/2019 e de acordo com a Lei Complementar 87/1996, com suas ulteriores modificações. São Paulo: Malheiros, 2020.

CARVALHO, Paulo de Barros. Sobre os princípios constitucionais tributários. Revisa de Direito Tributário, São Paulo, v. 55, n. 55, p. 143-155, 1991.

. Curso de Direito Tributário, 28 ${ }^{\mathrm{a}}$ ed. São Paulo: Saraiva, 2017.

COÊLHO, Sacha Calmon Navarro. Curso de Direito Tributário Brasileiro, 9a ed. Rio de Janeiro: Forense, 2007.

Curso de Direito Tributário Brasileiro, 14를 ed. Rio de Janeiro: Forense, 2015. 
COSTA, Regina Helena. Princípio da Capacidade Contributiva. São Paulo: Malheiros, 1993.

MELO, José Eduardo Soares de. ICMS: teoria e prática, $15^{\mathrm{a}} \mathrm{ed}$. rev. e atual. Porto Alegre: Livraria do Advogado Editora, 2020.

MOREIRA, André Mendes. A Não-Cumulatividade dos Tributos, $4^{a}$ ed. rev. e atual. São Paulo: Noeses, 2020.

PAULSEN, Leandro. Curso de Direito Tributário Completo, 9 ed. São Paulo: Saraiva Educação, 2018.

SANTA CATARINA (Estado). Governo do Estado. Lei no 10.297, de 26 de dezembro de 1996. Dispõe sobre o Imposto sobre Operações Relativas à Circulação de Mercadorias e sobre Prestações de Serviços de Transporte Interestadual e Intermunicipal e de Comunicação - ICMS e adota outras providências. Florianópolis, SC: Governo do Estado, [2021]. Disponível em: http://legislacao.sef.sc.gov.br/html/leis/1996/lei_96_10297.htm. Acesso em: 20 jun. 2021.

TORRES, Ricardo Lobo. Curso de Direito Financeiro e Tributário, 16 ed. São Paulo: Renovar, 2009.

Tratado de Direito Constitucional Financeiro e Tributário: valores e princípios constitucionais tributários. 2. ed. v. 2. Rio de Janeiro: Renovar, 2014.

\section{APÊNDICE- REFERÊNCIA DE NOTA DE RODAPÉ}

3. Excepcionalmente, poderá a União criar o imposto por força dos artigos 147 e 154, ambos da Constituição Federal (BRASIL, 2021c).

4. Para melhor visualização, sugere-se a análise dos seguintes boletins: https://sisweb.tesouro.gov.br/apex/f?p=2501:9::::9:P9_ID_PUBLICACAO:38233 (BRASIL, 2021); 
https://sisweb.te,souro.gov.br/apex/f?p=2501:9::::9:P9_ID_PUBLICACAO:32076 (BRASIL, 2021).

5. Decreto-lei № 4.657, de 4 de setembro de 1942 (BRASIL, 2021a): "Art. $4^{\circ}$ Quando a lei for omissa, o juiz decidirá o caso de acordo com a analogia, os costumes e os princípios gerais de direito."

6. "Art. 145. A União, os Estados, o Distrito Federal e os Municípios poderão instituir os seguintes tributos:

I - impostos; $[\ldots]$

$\S 1$ ำ Sempre que possível, os impostos terão caráter pessoal e serão graduados segundo a capacidade econômica do contribuinte, facultado à administração tributária, especialmente para conferir efetividade a esses objetivos, identificar, respeitados os direitos individuais e nos termos da lei, o patrimônio, os rendimentos e as atividades econômicas do contribuinte." (BRASIL, 2021c).

7. "Art. 153. Compete à União instituir impostos sobre: [...]

IV - produtos industrializados; [...]

$\S 3^{\circ} \mathrm{O}$ imposto previsto no inciso IV: [...]

I - será seletivo, em função da essencialidade do produto;" (BRASIL, 2021c).

8. "Artigo 23. Compete aos Estados e ao Distrito Federal instituir impostos sobre: [...]

II - operações relativas à circulação de mercadorias realizadas por produtores, industriais e comerciantes, imposto que não será cumulativo e do qual se abaterá, nos termos do disposto em lei complementar, o montante cobrado nas anteriores pelo mesmo ou por outro Estado. A isenção ou não-incidência, salvo determinação em contrário da legislação, não implicará crédito de imposto para abatimento daquele incidente nas operações seguintes. [...] 
$\S 5^{\circ}$ - A alíquota do imposto a que se refere o item II será uniforme para todas as mercadorias nas operações internas e interestaduais, bem como nas interestaduais realizadas com consumidor final; o Senado Federal, mediante resolução tomada por iniciativa do Presidente da República, fixará as alíquotas máximas para cada uma dessas operações e para as de exportação." (BRASIL, 2021b).

9. Extrafiscalidade pode ser definida como sendo o "emprego dos meios tributários para fins não ficais, mas ordinários, isto é, para disciplinar comportamentos de virtuais contribuintes, induzindo-os a fazer ou deixar de fazer alguma coisa" (CARRAZZA, 2020, p. 464).

10. "Não existe, porém entidade tributária que se possa dizer pura, no sentido de realizar tão só a fiscalidade, ou, unicamente, a extrafiscalidade. Os dois objetivos convivem, harmônicos, na mesma figura impositiva, sendo apenas lícito verificar que, por vezes, um predomina sobre o outro." (CARVALHO, 2017, p. 172).

11. Lei no 10.297, de 26 de dezembro de 1996 (SANTA CATARINA, 2021): "Art. 19. As alíquotas do imposto, nas operações e prestações internas, inclusive na entrada de mercadoria importada e nos casos de serviços iniciados ou prestados no exterior, são:

I - 17\% (dezessete por cento), salvo quanto às mercadorias e serviços relacionados nos incisos II a IV;

II $-25 \%$ (vinte e cinco por cento) nos seguintes casos:

1. a) operações com energia elétrica;

2. b) operações com os produtos supérfluos relacionados na Seção I do Anexo I desta Lei;

3. c) prestações de serviços de comunicação; [...]".

12. A tese proposta pelo relator é a seguinte: "Adotada, pelo legislador estadual, a técnica da seletividade em relação ao ICMS, discrepam do figurino constitucional alíquotas sobre as operações de energia elétrica e serviços de telecomunicação em 
patamar superior ao das operações em geral, considerada a essencialidade dos bens e serviços" (BRASIL, em julgamento).

13. O ministro propôs as seguintes teses: "I. Não ofende o princípio da seletividade/essencialidade previsto no artigo 155, § 2º , III, da Constituição Federal a adoção de alíquotas diferenciadas do ICMS incidente sobre energia elétrica, considerando, além da essencialidade do bem em si, o princípio da capacidade contributiva. II. O ente tributante pode aplicar alíquotas diferenciadas em razão da capacidade contributiva do consumidor, do volume de energia consumido e/ou da destinação do bem. III. A estipulação de alíquota majorada para os serviços de telecomunicação, sem adequada justificativa, ofende o princípio da seletividade do ICMS" (BRASIL, em julgamento).

Enviado: Agosto, 2021.

Aprovado: Agosto, 2021. 